\title{
Optical properties of $\mathrm{Er}^{3+}$ doped phosphate glasses
}

\section{Mahmoud Mohammed Ismail*, ${ }^{1}$ Hazem Farouk, ${ }^{2}$ Mohamed Ali Salem, ${ }^{1}$ Adel Ashery, Inas Kamal Battisha ${ }^{1}$}

${ }^{1}$ National Research Centre, Solid State Physics Department,Physics Research Division,33 El Behooth St., Dokki, Giza, Egypt, (Affiliation ID: 60014618).

${ }^{2}$ Al AZHAR University, Physics department, faculty of science, Cairo, Egypt.

\begin{abstract}
:
$\mathrm{Er}^{3+}$-doped Na-Al-Ba-K phosphate glasses were prepared by melt quenching technique. The absorbance spectrum was measured and hence the absorption coefficient, absorption cross-secion were calculated. The emission cross-section has been evaluated using Mc-Cumber theory. The gain has been evaluated as a function of population inversion which show that the amplification action would be achieved around $1596 \mathrm{~nm}$ for a population inversion of only $20 \%$. The Judd-Ofelt analysis has been carried out and hence the radiative properties of ${ }^{4} I_{13 / 2} \rightarrow{ }^{4} I_{15 / 2}$ and ${ }^{4} S_{3 / 2} \rightarrow{ }^{4} I_{15 / 2}$ transitions were obtained. Higher radiative lifetime for the ${ }^{4} I_{13 / 2}$ level of $\mathrm{Er}^{3+}$ ion has been noticed compared to the other $\mathrm{Er}^{3+}$ doped glasses. These results clearly indicate that the present glasses are suitable for laser as well as optical amplifiers around $543 \mathrm{~nm}$ and $1522 \mathrm{~nm}$.
\end{abstract}

Keywords :- Phosphate glass, Erbium, Judd-Ofelt, Mc-Cumber, Optical properties

\section{Introduction}

In recent years, great efforts dedicated to study the optical properties of trivalent erbium $\left(\mathrm{Er}^{3+}\right)$ ions -doped different glasses for the development of optical devices such as solid state lasers, optical sensors and optical amplifiers, etc. $\mathrm{Er}^{3+}$ ion exhibits prominent emissions around $1522 \mathrm{~nm}$ corresponding to ${ }^{4} I_{13 / 2} \rightarrow{ }^{4} I_{15 / 2}$ transition. This transition attracted attention since it is located in the so-called ultra low-loss telecommunication window of glass, extending from around 1450 to $1600 \mathrm{~nm}$ and it is also located in the eye-safe spectral region[M. Yamada 1997, Y. Ohishi 1998]. In addition, $\mathrm{Er}^{3+}$ ion emits green emission around $540 \mathrm{~nm}$ corresponds to ${ }^{4} S_{3 / 2} \rightarrow{ }^{4} I_{15 / 2}$ transition which could be useful for green laser applications [A. Lira 2004].

The optical properties of rare earth (R.E) ions depend on their local environment in which they are incorporated. In other words, the surrounding ligand field has a considerable influence on the optical properties of the R.E ion such as the absorption and emission cross-section, spectral shapes of the emission and absorption bands as well as excited state lifetimes, which are the key factors in amplification and lasing processes.

*Corresponding author : mah_m1985@yahoo.com 
Other than optical properties, the host materials should have good thermal, mechanical and chemical stability to be suitable for high performance optical devices. The phosphate based multi-component glasses have received enormous interest because of high R.E ions solubility without clustering, low non-linear refractive index [M.Yamane and Y.Asahara 2004] and the phonon energy of phosphate glasses $\left(\sim 1200 \mathrm{~cm}^{-1}\right)$, makes it almost insensitive to up-conversion phenomena [Digonett 2001].

The main purpose of this work is dedicated to prepare multi-componant phosphate glasses doped with $\mathrm{Er}^{3+}$ ions. The structure, composition, physical and optical properties of the prepared sample will be evaluated.

\section{Experimental details}

\subsection{Glass preparation}

Phosphate glasses with the composition (mol\%) of $60 \% \quad \mathrm{P}_{2} \mathrm{O}_{5}+8 \% \mathrm{Al}_{2} \mathrm{O}_{3}+2 \% \mathrm{Na}_{2} \mathrm{O}+$ $13 \% \mathrm{BaO}+(17-\mathrm{x}) \% \mathrm{~K}_{2} \mathrm{O}+\mathrm{x} \% \mathrm{Er}_{2} \mathrm{O}_{3}(\mathrm{x}=0.2,0.75$, and $1.5 \%)$ were prepared using conventional melt quenching technique which symbolic as PANBK0.2Er, PANBK0.75Er, and PANBK1.5Er.

High purity $\mathrm{P}_{2} \mathrm{O} 5, \mathrm{Al}_{2} \mathrm{O}_{3}, \mathrm{Na}_{2} \mathrm{CO}_{3}, \mathrm{BaCO}_{3}, \mathrm{~K}_{2} \mathrm{CO}_{3}$, and $\mathrm{Er}\left(\mathrm{NO}_{3}\right)_{3} 5 \mathrm{H}_{2} \mathrm{O}$ were used as starting materials to prepare the glasses. A batch of 30 grams of starting materials was thoroughly mixed in agate mortar and the homogeneous mixture was taken in a Porcelain crucible and kept in an electric furnace at a temperature of $1100^{\circ} \mathrm{C}$ for $2 \mathrm{~h}$. The melt was then poured onto a preheated stainless steel mold at a temperature of $430{ }^{0} \mathrm{C}$ until the glass solidifies. Then the glass samples were annealed at the same temperature $430{ }^{0} \mathrm{C}$ for 10 hours to remove thermal strains and stress. After that the samples were allowed to cool to room temperature. Finally, the prepared glasses were cut and polished for optical measurements.

\subsection{Characterization techniques}

The density of the samples was determined by Archimede's method with water as an immersion liquid. The refractive indices of this glasses were measured using PTR 46X refractometer at $589 \mathrm{~nm}$ with the monobromonapthalene as the contact layer between the Samples and prism of the refractometer. X-ray diffraction (XRD) patterns for the prepared samples were recorded with a Philips X-ray diffractometer using monochromatized $\mathrm{CuK}_{\alpha 1}$ radiation of wavelength $1.54056 \AA$ from a fixed source operated at $45 \mathrm{kV}$ and $9 \mathrm{~mA}$. SEM model QUANTA -FEG250 and operating at $35 \mathrm{kV}$ employed in the present work to study coarse and fine microstructures of the samples. Attached Energy dispersive X-ray (EDX) unit were used to study the atomic ratios of the elements for samples. Absorption spectra (200-1800 nm) were measured using a UV/VIS/NIR spectrophotometer Model V-570. The instrument specified by resolution $0.1 \mathrm{~nm}$ and wavelength accuracy $\pm 0.3 \mathrm{~nm}$ (at a spectral bandwidth of $0.5 \mathrm{~nm}$ ). The measurements were made on glasses and glasses powder, immediately after glass preparation and all spectra were measured at room temperature

\section{Results and discussion}

\subsection{Physical properties}

The density of the samples was determined by Archimede's method with water as an immersion liquid using the following relation 


$$
\rho=\frac{W_{a}}{W_{a}-W_{w}} \rho_{w}
$$

Where $W_{a}$ is the weight in air, $\mathrm{W}_{\mathrm{w}}$ is the weight in water, $\rho$ is the glass density and $\rho_{\mathrm{w}}$ is the density of water.

The average molecular weight of a given sample $\left(M_{w}\right)$ which composed of many elements is given by the following relation

$$
M_{w}=\sum r_{i} m_{i}
$$

Where $m_{i}$ is the atomic mass of the element and $r_{i}$ is the ratio of that element

The $\mathrm{Er}^{3+}$ ions concentration $(\mathrm{N})$ is obtained using the following relation[Reddy 2011].

$$
N\left(\text { ions } / c^{3}\right)=\frac{2 N_{a} \rho x}{M_{w}}
$$

where $\mathrm{x}$ is the molar ratio of $\mathrm{Er}^{3+}$ ions and $N_{a}$ is Avogadro's number.

Table 1 shows the density, ions concentration and average molecular weight of PANBK0.2Er, PANBK0.75Er and PANBK1.5Er glasses. It can be noticed that $M_{w}$, and $\rho$ slightly increase with the increase in Er content and this is due to that Er atom is much heavier than $\mathrm{K}$ atom.

Table 1. The physical properties of PANBK0.2Er, PANBK0.75Er and PANBK1.5Er glasses.

\section{Physical properties}

\begin{tabular}{cccc} 
Samples & \multicolumn{3}{c}{} \\
\cline { 2 - 4 } & $\boldsymbol{\rho}\left(\mathrm{gm} / \mathrm{cm}^{3}\right)$ & $\mathbf{N}\left(\times 10^{+20}\right.$ ions $\left./ \mathrm{cm}^{3}\right)$ & $\boldsymbol{M}_{W}(\mathbf{g m})$ \\
PANBK0.2Er & 2.79 & 0.5123 & 131.08 \\
& & & 132.67 \\
\hline PANBK0.75Er & 2.80 & 1.9044 & 134.83 \\
\hline PANBK1.5Er & 2.82 & 3.77313 & \\
\hline
\end{tabular}

\subsection{XRD}

Fig .1 shows the XRD patterns of the samples doped with different concentrations of $\mathrm{Er}^{3+}$. Very broad hump extending from $2 \Theta=12$ up to $40^{\circ}$ is observed. No diffraction patterns were noticed all over the measured range for all of the samples which confirm the amorphous nature of our glasses. 


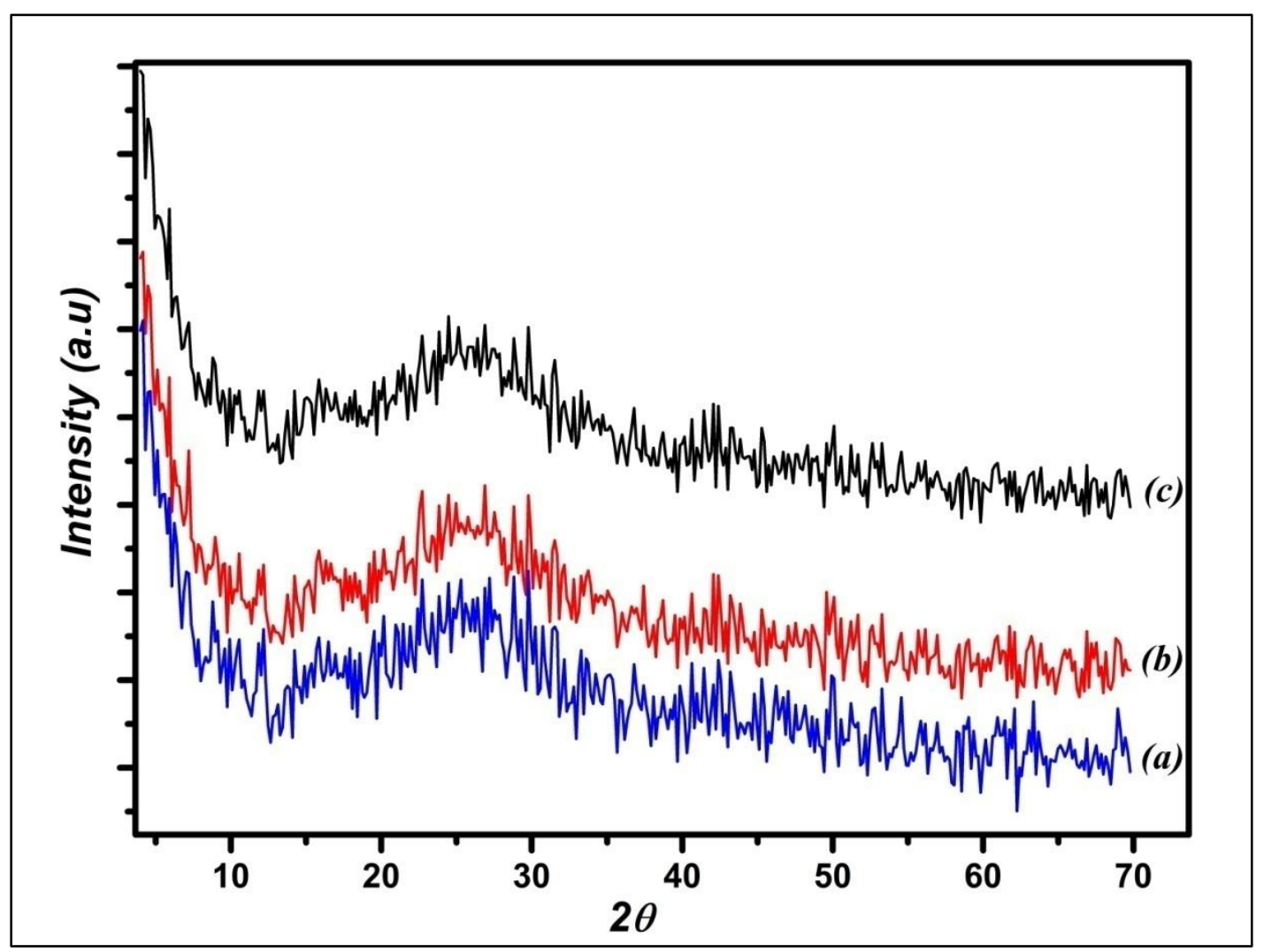

Fig.1. The XRD patterns of PANBK0.2Er (a), PANBK0.75Er (b) and PANBK1.5Er (c).

\subsection{SEM.}

Fig. 2 shows the SEM images of the PANBK0.2Er as a representative sample. The SEM images show the surface morphology of the samples. The appeared smooth surfaces confirm the dense nature presence of the glass matrix. We couldn't identify any grain boundaries from the surface morphological image which confirms the amorphous nature of the samples. The obtained data coincides with XRD spectra.

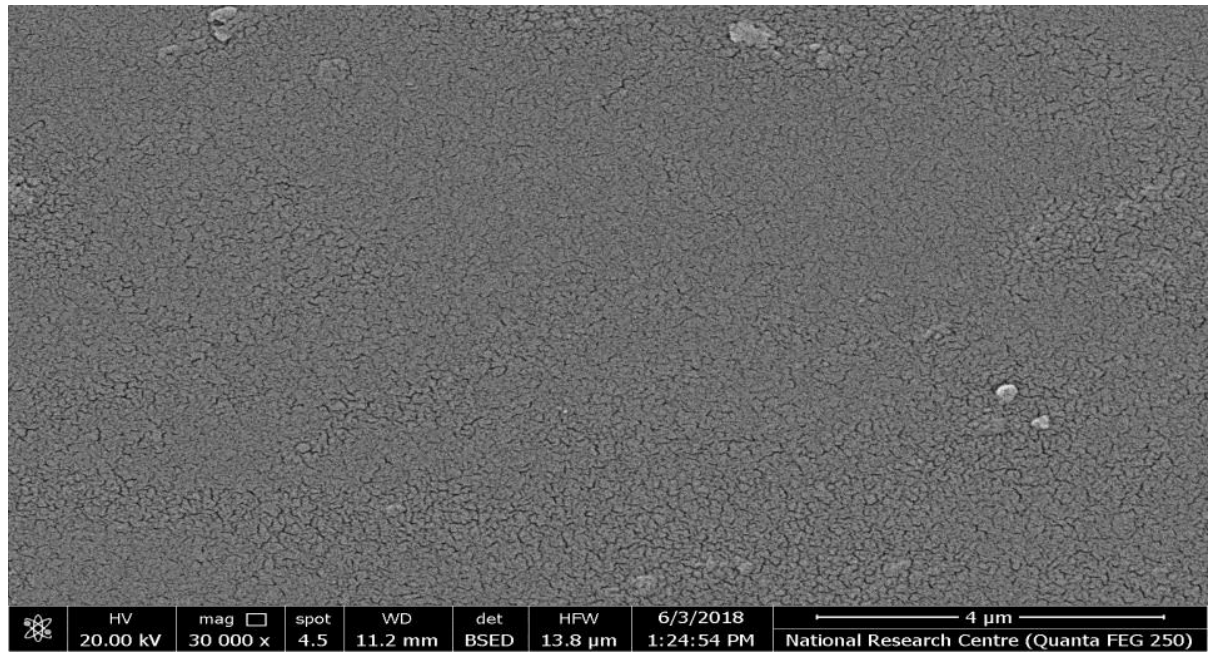

Fig.2. The FESEM images of the PANBK0.2Er sample. 


\section{$3.4 E D X$}

Fig.3 shows the EDAX spectra of the PANBK0.2Er glass sample. The EDX spectra confirm the existence of Phosphate, Aluminum, Sodium, Potassium, Barium and Erbium in the glass matrix.

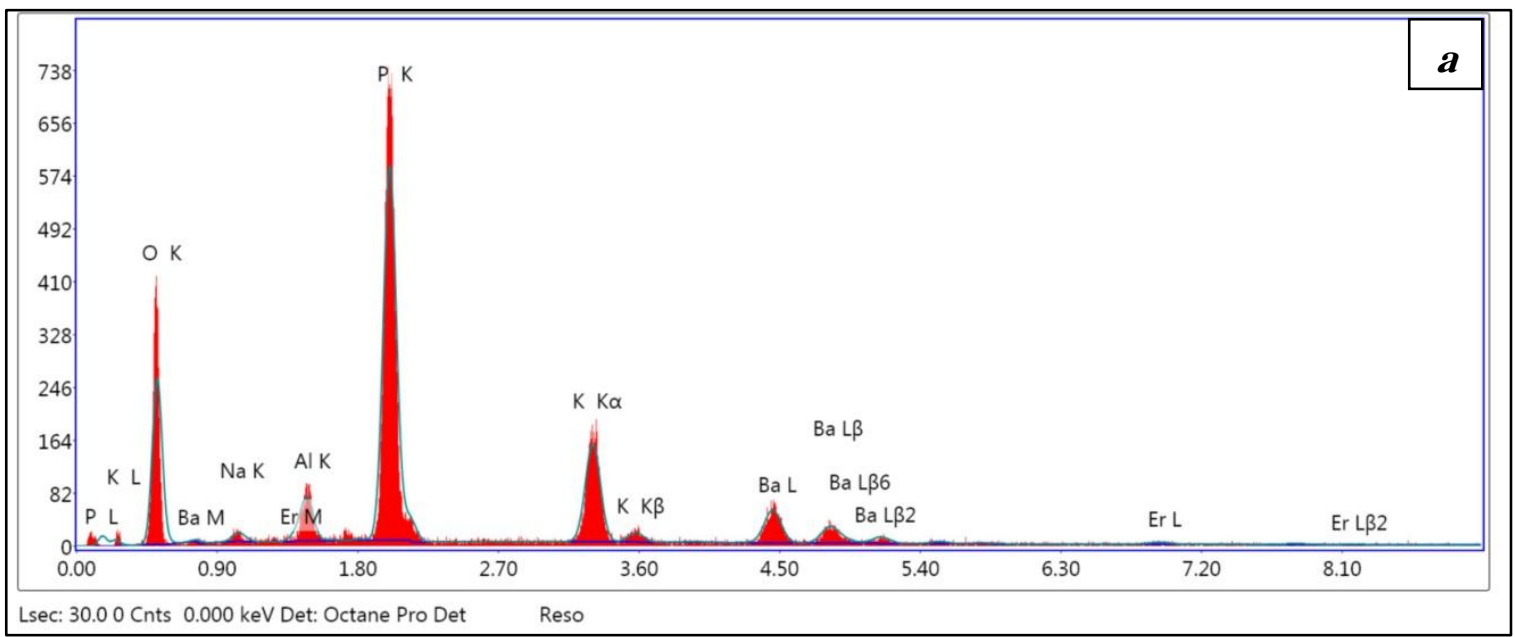

Fig.3. The EDX spectra of the PANBK0.2Er.

Table 2 shows the atomic ratios of the elements and the oxygen to phosphate ratio for PANBK0.2Er glass, they are equal to $2.985 \%$ and 2.994, respectively, which indicate that the glasses are almost a meta-phosphate glasses.

Table 2. The atomic ratios of elements and oxygen to phosphate ratio for PANBK1.0Er and PANBK0.5Er glasses.

\begin{tabular}{lllllllll}
\hline Sample & $\boldsymbol{P}$ & $\boldsymbol{A l}$ & $\mathrm{Na}$ & $\boldsymbol{K}$ & $\mathbf{B a}$ & $\boldsymbol{E r}$ & $\boldsymbol{O}$ & $\boldsymbol{O} / \boldsymbol{P}$ ratio \\
\hline PANBK0.2Er & $21.5 \%$ & $2.68 \%$ & $1.25 \%$ & $6.8 \%$ & $2.7 \%$ & $0.2 \%$ & $64.84 \%$ & $3.016 \%$ \\
\hline
\end{tabular}

\subsection{Optical properties}

Fig.4 shows absorption Coefficient spectra of PANBK1.5Er glass as a representative data in the region extended from 300 up to $1650 \mathrm{~nm}$. The spectrum consists of 11 bands corresponding to the transitions from the ground state ${ }^{4} I_{15 / 2}$ to the various excited states ${ }^{4} I_{13 / 2}$, ${ }^{4} I_{11 / 2},{ }^{4} I_{9 / 2},{ }^{4} F_{9 / 2},{ }^{4} S_{3 / 2},{ }^{2} H_{11 / 2},{ }^{4} F_{7 / 2},{ }^{4} F_{5 / 2},{ }^{2} G_{9 / 2},{ }^{4} G_{11 / 2}$ and ${ }^{4} G_{9 / 2}+{ }^{2} K_{15 / 2}$, respectively. The absorption bands are assigned to the energy levels of reported $\mathrm{Er}^{+3}$ glass systems [Babu 2007 , C.C.Santos 2009, Reddy 2011, Luewarasirikul 2018]. 


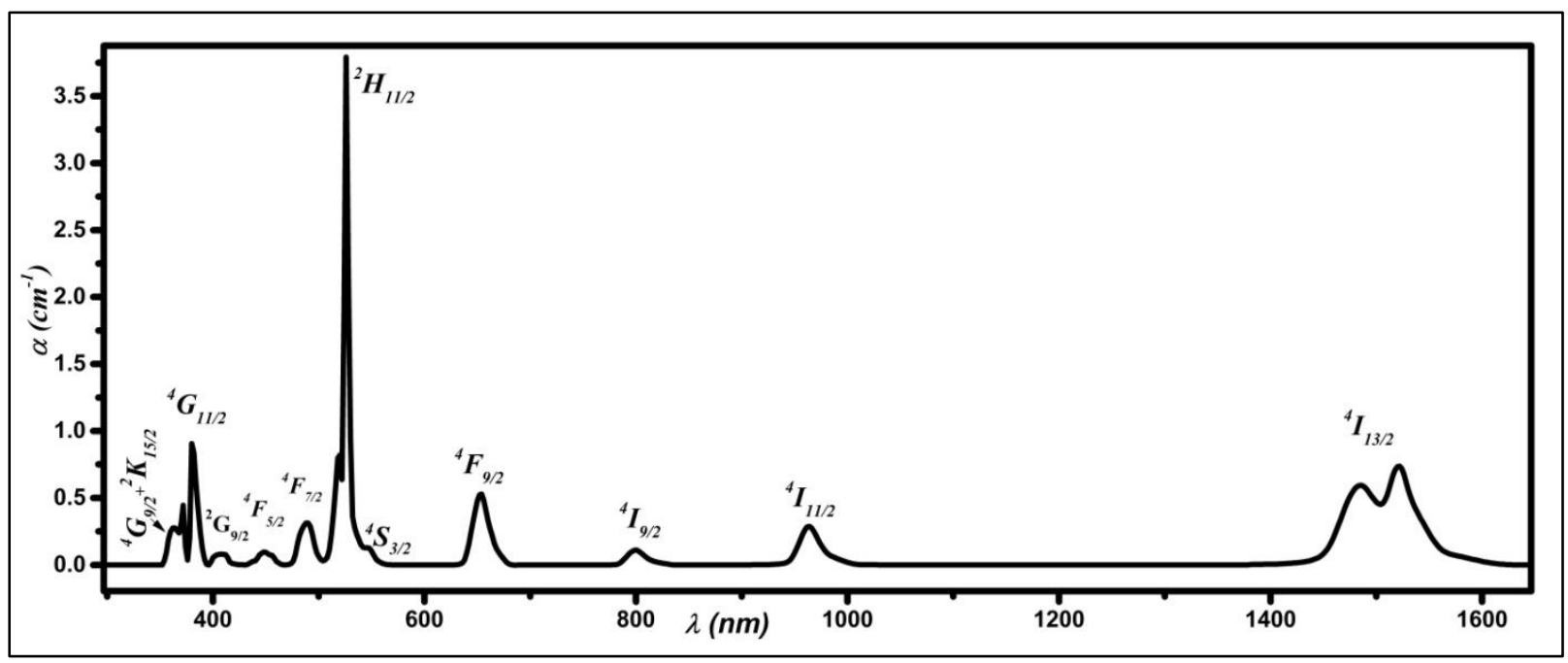

Fig.4. The absorption Coefficient spectra of PANBK1.5Er glass.

The electrostatic $\mathrm{F}_{(2)}, \mathrm{F}_{(4)}, \mathrm{F}_{(6)}$ and spin-orbit $(\zeta)$ parameters were obtained using standard leastsquare fitting approach between calculated barycenter energies and experimental barycenter energies using RELEC program [RELIC 2013]. The calculations were made for PANBK1.5Er and the results are shown in Table. 3 as a representative data .

Table.3. $\left.\mathrm{F}_{(2)}, \mathrm{F}_{(4)}, \mathrm{F}_{(6)}\right)$ and $\zeta$ parameters for PANBK1.5Er

$$
\begin{array}{ll}
F_{(2)} & 431.3
\end{array}
$$

\section{$\boldsymbol{F}_{(4)}$}

$\boldsymbol{F}_{(\boldsymbol{6})}$

$\boldsymbol{Z}$
66.7

\section{3}

2436.5

The experimental oscillator strengths $\left(f_{\text {exp }}\right)$ for all the absorption bands of $\mathrm{Er}^{3+}$ ions can be determined from the absorption spectra using the expression given by (equation 4) [Judd 1962].

$$
f_{\exp }\left(\Psi J \rightarrow \Psi^{\prime} J^{\prime}\right)=\frac{m c^{2}}{\pi e^{2}} \int \varepsilon(v) d v=4.318 \times 10^{-9} \int \varepsilon(v) d v
$$

where $\mathrm{m}$ and e are the mass and the charge of the electron, respectively, $\mathrm{c}$ is the speed of light and $v$ is the wavenumber $\left(\mathrm{cm}^{-1}\right)$.

According to Jude-Ofelt theory [Judd 1962, Ofelt 1962] the total oscillator strength can be calculated using equation (5)

$$
f_{\text {calc }}\left(\Psi J \rightarrow \Psi^{\prime} J^{\prime}\right)=\frac{8 \pi^{2} m v_{0}}{3 h(2 j+1) n^{2}}\left[\chi_{e d} S_{e d}+\chi_{m d} S_{m d}\right]
$$

Where $S_{e d}$ and $S_{m d}$ the electric and magnetic dipole strengths, $\chi_{e d}=n\left(n^{2}+2\right)^{2} / 9$ and $\chi_{m d}=$ $n^{3}$ are the Dexter correction for the local field in a medium of refractive index $n$ 


$$
\begin{gathered}
S_{e d}\left(\Psi J \rightarrow \Psi^{\prime} J^{\prime}\right)=\frac{8 \pi^{2} m v_{0} \chi_{e d}}{3 h(2 j+1) n^{2}}\left[\sum_{t=2,4,6} \Omega_{t}\left|\left\langle i \| U^{t}|| j\right\rangle\right|^{2}\right] \\
S_{m d}\left(\Psi J \rightarrow \Psi^{\prime} J^{\prime}\right)=\frac{e^{2} h^{2} \chi_{m d}}{16 \pi^{2} m^{2} c^{2}}|\langle i|| L+2 S|| j\rangle|^{2}
\end{gathered}
$$

Where $\Omega_{\mathrm{t}}\left(\mathrm{t}=2,4\right.$, and 6) are Jude-Ofelt intensity parameters, $\mathrm{m}$ is the electron mass, $\boldsymbol{v}_{0}$ is the wavenumber at the maximum absorption $\left(\mathrm{cm}^{-1}\right), 2 J+1$ is the degeneracy of the originating level of the transition, $\mathrm{h}$ is the Plank constant $=6.6261 \times 10-27 \mathrm{erg} . \mathrm{sec}$, and $\left\langle i \| U^{t}|| j\right\rangle$ are the doubly reduced matrix elements of the tensor transition operator and they have been calculated as in [Mohan 2007, P.Hehlen 2013] using [RELIC 2013].

The intensity parameters, $\Omega_{\mathrm{t}}(\mathrm{t}=2,4$, and 6$)$ can be determined using least-square fitting approach between calculated $\left(f_{\text {calc }}\right)$ and experimental $\left(f_{\text {exp }}\right)$ oscillator strength.

The J.O parameters are sensitive to the glass composition. The value of $\Omega_{2}$ is pointing to covalent bonding between surrounding ligands and rare earth ions, whereas $\Omega_{4}$ and $\Omega_{6}$ parameters are related to the rigidity of the medium [Jorgensen and Reisfeld 1983]. The $\Omega_{\mathrm{t}}$ parameters of PANBK1.5Er glass compared to other reported data are tabulated inTable.4. It can be seen that the $\Omega_{t}$ parameters of the prepared glass is smaller than the other glasses which indicates that lower rigidity of the medium, lower covalency of the Er-O bond and asymmetry around $\mathrm{Er}^{3+}$ site. The spectroscopic quality factor $\left(\chi=\Omega_{4} / \Omega_{6}\right)$ is important inpredicting the lasing transitions in a given matrix [Qiao 2004]. The value of $\chi$ for the PANBK1.5Er glass has been calculated to be 0.795 and compared with those of the reported $\mathrm{Er}^{3+}$ glasses in Table.4. The value of $\chi$ for the present glass is larger than Phosphate [Babu 2007] but smaller than Sodium phosphate [Reddy 2011], Fluoride phosphate [Linganna 2015] and Antimony-borate[Qian 2010] glass, Lead phosphate [C.C.Santos 2009], Silicate [Qian 2008] glass and $\mathrm{CaSc}_{2} \mathrm{O}_{4}$ [Georgescu 2018] glass.

Table.4. The Judd-Ofelt parameters $\left(\Omega_{\mathrm{t}} \times 10^{-20} \mathrm{~cm}^{2}\right)$, trend and spectroscopic quality factor $\left(\chi=\Omega_{4} / \Omega_{6}\right)$ for PANBK1.5Er glass with other reported $\mathrm{Er}^{+3}$-doped systems.

\begin{tabular}{lccccc}
\hline HOST MATRIX & $\Omega_{2}$ & $\Omega_{4}$ & $\Omega_{6}$ & $\chi=\Omega_{4} / \Omega_{6}$ & Trend \\
\hline PANBK1.5Er & 0.43 & 0.31 & 0.39 & 0.795 & $\Omega_{2}>\Omega_{6}>\Omega_{4}$ \\
$\begin{array}{l}\text { Present work } \\
\text { Phosphate }\end{array}$ & 8.05 & 1.46 & 2.28 & 0.64 & $\Omega_{2}>\Omega_{6}>\Omega_{4}$ \\
[Babu 2007] & & & & \\
$\begin{array}{l}\text { Sodium } \\
\text { phosphate }\end{array}$ & 3.26 & 0.57 & 0.55 & 1.04 & $\Omega_{2}>\Omega_{4}>\Omega_{6}$ \\
{$\left[\begin{array}{l}\text { Reddy 2011] } \\
\text { Lead phosphate }\end{array}\right.$} & 12.50 & & & & \\
$\begin{array}{l}\text { [C.C.Santos } \\
\text { 2009] }\end{array}$ & 4.00 & 3.00 & 1.33 & $\Omega_{2}>\Omega_{4}>\Omega_{6}$ \\
$\begin{array}{l}\text { Fluoride } \\
\text { phosphate }\end{array}$ & 4.70 & 1.60 & 1.60 & 1.00 & \\
\hline
\end{tabular}




\begin{tabular}{|c|c|c|c|c|c|}
\hline \multicolumn{6}{|c|}{ [Linganna 2015] } \\
\hline $\begin{array}{l}\text { Silicate [Qian } \\
\text { 2008] }\end{array}$ & 4.20 & 1.85 & 1.62 & 1.14 & $\Omega_{2}>\Omega_{4}>\Omega_{6}$ \\
\hline $\begin{array}{l}\text { Antimony- } \\
\text { borate[Qian } \\
2010]\end{array}$ & 2.63 & 1.04 & 1.09 & 0.95 & $\Omega_{2}>\Omega_{6}>\Omega_{4}$ \\
\hline $\begin{array}{l}\mathrm{CaSc}_{2} \mathrm{O}_{4} \\
\text { [Georgescu } \\
\text { 2018] }\end{array}$ & 3.42 & 1.66 & 0.76 & 2.18 & $\Omega_{2}>\Omega_{4}>\Omega_{6}$ \\
\hline
\end{tabular}

Table 5 shows the experimental peak position $\left(E_{\text {exp }} \mathrm{cm}^{-1}\right)$, calculated peak position $\left(\boldsymbol{E}_{\text {calc }}\right.$ $\left.\mathrm{cm}^{-1}\right)$, experimental oscillator strengths $\left(f_{\exp } \times 10^{6}\right)$, calculated oscillator strengths $\left(f_{\text {calc }} \times 10^{6}\right)$ and Jude-Ofelt intensity parameters for different transitions of $\mathrm{Er}^{3+}$ ions in PANBK1.5Er glass. The good agreement between experimental and calculated parameters indicates the accurate fitting of Jude-Ofelt parameters and electrostatic parameters.

Table 5. The $E_{\text {exp }}, E_{\text {calc }}, f_{\text {exp }}, f_{\text {calc }}$ and Jude-Ofelt intensity parameters for different transitions of $\mathrm{Er}^{+3}$ ions in PANBK1.5Er glass.

\begin{tabular}{|c|c|c|c|c|c|}
\hline \multirow{2}{*}{ Initial level } & \multirow{2}{*}{ Final level } & \multicolumn{2}{|c|}{ Energy $\left(\mathrm{cm}^{-1}\right)$} & \multicolumn{2}{|c|}{$F \times 10^{-6}$} \\
\hline & & $E_{\text {exp }}$ & $E_{c a l c}$ & $f_{\text {exp }}$ & $F_{\text {calc }}$ \\
\hline${ }^{4} \boldsymbol{I}_{15 / 2}$ & ${ }^{4} \boldsymbol{I}_{13 / 2}$ & 6639.8 & 6676.8 & 0.66 & 0.93 \\
\hline${ }^{4} I_{15 / 2}$ & ${ }^{4} I_{11 / 2}$ & 10345.2 & 10303.5 & 0.23 & 0.18 \\
\hline${ }^{4} I_{15 / 2}$ & ${ }^{4} I_{9 / 2}$ & 12497.9 & 13364 & 0.09 & 0.09 \\
\hline${ }^{4} I_{15 / 2}$ & ${ }^{4} F_{9 / 2}$ & 15281.9 & 15213.2 & 0.7 & 0.52 \\
\hline${ }^{4} I_{15 / 2}$ & ${ }^{4} S_{3 / 2}$ & 18153.5 & 18280.1 & 0.2 & 0.16 \\
\hline${ }^{4} I_{15 / 2}$ & ${ }^{2} H_{11 / 2}$ & 19080.7 & 19218.7 & 2.7 & 0.96 \\
\hline${ }^{4} I_{15 / 2}$ & ${ }^{4} \boldsymbol{F}_{7 / 2}$ & 20496.1 & 20381.9 & 0.57 & 0.61 \\
\hline${ }^{4} I_{15 / 2}$ & ${ }^{4} F_{5 / 2}$ & 22268.9 & 22019.1 & 0.25 & 0.2 \\
\hline${ }^{4} I_{15 / 2}$ & ${ }^{2} \boldsymbol{G}_{\boldsymbol{g} / 2}$ & 24574.8 & 24583.3 & 0.19 & 0.24 \\
\hline${ }^{4} I_{15 / 2}$ & ${ }^{4} G_{11 / 2}$ & 26121.6 & 26513.4 & 1.29 & 1.55 \\
\hline$\Omega_{2}$ & $\Omega_{4}$ & $\Omega_{6}$ & & & \\
\hline $0.43 \times 10^{-20}$ & $0.31 \times 10^{-20}$ & $0.39 \times 10^{-20}$ & & & \\
\hline
\end{tabular}


Once the Jude-Ofelt parameters have been obtained, some important radiative parameters can be derived such as :-

The spontaneous emission probability $(A)$ of an electric-dipole transition is given by the following equation[Weber 1967].

$$
A_{r}\left(\Psi J \rightarrow \Psi^{\prime} J^{\prime}\right)=\frac{64 \pi^{4} v_{0}^{2} e^{2}}{3 h(2 j+1)}\left[\frac{n\left(n^{2}+1\right)^{2}}{9} S_{e d}+n^{3} S_{m d}\right]
$$

Where $S_{e d}$ and $S_{m d}$ are the electric and magnetic dipole line strengths respectively which are expressed as

$$
\begin{gathered}
S_{e d}\left(\Psi J \rightarrow \Psi^{\prime} J^{\prime}\right)=\sum_{t=2,4,6} \Omega_{t}\left|\left\langle J|| U^{t}|| J^{\prime}\right\rangle\right|^{2} \\
S_{m d}\left(\Psi J \rightarrow \Psi^{\prime} J^{\prime}\right)=\frac{h^{2}}{16 \pi^{2} m^{2} c^{2}}\left|\left\langle J|| L+2 S|| J^{\prime}\right\rangle\right|^{2}
\end{gathered}
$$

The total radiative transition probability $A_{t}(\Psi J)$ for an excited level is given by the sum of the $A\left(\Psi J \rightarrow \Psi^{\prime} J^{\prime}\right)$ terms calculated over all terminal levels [Weber 1967].

$$
A_{t}(\Psi J)=\sum A\left(\Psi J \rightarrow \Psi^{\prime} J^{\prime}\right)
$$

The fluorescence branching ratio $B_{r}$ has been determined using

$$
B_{r}=\frac{A\left(\Psi J \rightarrow \Psi^{\prime} J^{\prime}\right)}{A_{t}(\Psi J)}
$$

The radiative lifetime $\tau_{r}(\Psi J)$ of an excited level $(\Psi J)$ is given by the reciprocal of $A_{t}(\Psi J)[$ Weber 1967].

$$
\tau_{r}(\Psi J)=\frac{1}{A_{t}(\Psi J)}
$$

The $A, \tau_{r}$ and $\beta_{\mathrm{r}}$ for the emission levels of $\mathrm{Er}^{3+}$ ions for PANBK1.5Er glass, are presented in

Table.6. The $\tau_{r}$ for the ${ }^{4} I_{13 / 2} \rightarrow{ }^{4} I_{15 / 2}$ transition is about $11.53 \mathrm{~ms}$. It can be observed that the $\tau_{r}$ for the present glass is much higher than, calcium barium phosphate glasses [Luewarasirikul 2018] $\left(\tau_{\mathrm{r}}=2.7 \mathrm{~ms}\right)$, lead phosphate $\left(\tau_{\mathrm{r}}=3.7 \mathrm{~ms}\right)$ [C.C.Santos 2009], silicate $\left(\tau_{\mathrm{r}}\right.$ $=3.82 \mathrm{~ms})$ [Qian 2008], phosphate $\left(\tau_{\mathrm{r}}=4.82 \mathrm{~ms}\right)$ [Babu 2007] and sodium phosphate $\left(\tau_{\mathrm{r}}=10.57\right.$ $\mathrm{ms})$ [Reddy 2011]. Hence, the prepared phosphate glasses can be considered very promising to active laser application. The same thing for the green line emission at $543 \mathrm{~nm}$ for the ${ }^{4} S_{3 / 2} \rightarrow{ }^{4} I_{15 / 2}$ transition, it have high radiative lifetime $\left(\tau_{r}=1.749 \mathrm{~ms}\right)$ and high branching ratio $\left(\beta_{\mathrm{R}}=0.67212\right)$. 


\begin{tabular}{ccccc}
\multicolumn{5}{c}{ Table.6. $A_{\text {rad }}, \tau_{r}$ and $\beta_{\mathrm{r}}$ for the ${ }^{4} S_{3 / 2} \rightarrow{ }^{4} I_{15 / 2}$ and ${ }^{4} I_{13 / 2} \rightarrow{ }^{4} I_{15 / 2}$ transitions } \\
of Er ${ }^{+3}$ ions in PANBK1.5Er glass.
\end{tabular}

McCumber equation [McCumber 1964] relates absorption and emission cross-section as follows :-

$$
\sigma \mathrm{e}(v)=\sigma \mathrm{a}(v) e^{(\varepsilon-\mathrm{h} v) / K_{B} T}
$$

Where $\varepsilon$ is as the net free energy required to excite one $\mathrm{Er}^{3+}$ ion from the ${ }^{4} I_{15 / 2}$ to the ${ }^{4} I_{13 / 2}$ state at temperature $T$. The absorption cross-section $\left(\sigma_{\mathrm{a}}\right)$ has been calculated by equation (15) [Miniscalco and Quimby 1991].

$$
\sigma_{a}=2.302 \frac{A}{N L}
$$

where $\mathrm{A}$ is the absorbance, $N$ is the $\mathrm{Er}^{+3}$ ion concentration per cubic $\mathrm{cm}$ and $\mathrm{L}$ is the sample thickness.

The absorption $\left(\sigma_{\mathrm{a}}\right)$ and emission $\left(\sigma_{\mathrm{e}}\right)$ cross-sections of $\mathrm{Er}^{3+}$ ions ${ }^{4} I_{13 / 2} \rightarrow{ }^{4} I_{15 / 2}$ transition in PANBK1.5Er glass are presented in Fig.5. From this figure it is clear that the peaks of absorption and emission cross-sections of $\mathrm{Er}^{+3}$ are $1522 \mathrm{~nm}\left(\lambda_{\mathrm{p}}\right)$. At longer wavelengths $\sigma_{e}$ is higher than $\sigma_{a}$, and for shorter wavelengths $\sigma_{e}$ is smaller than $\sigma_{a}$. 


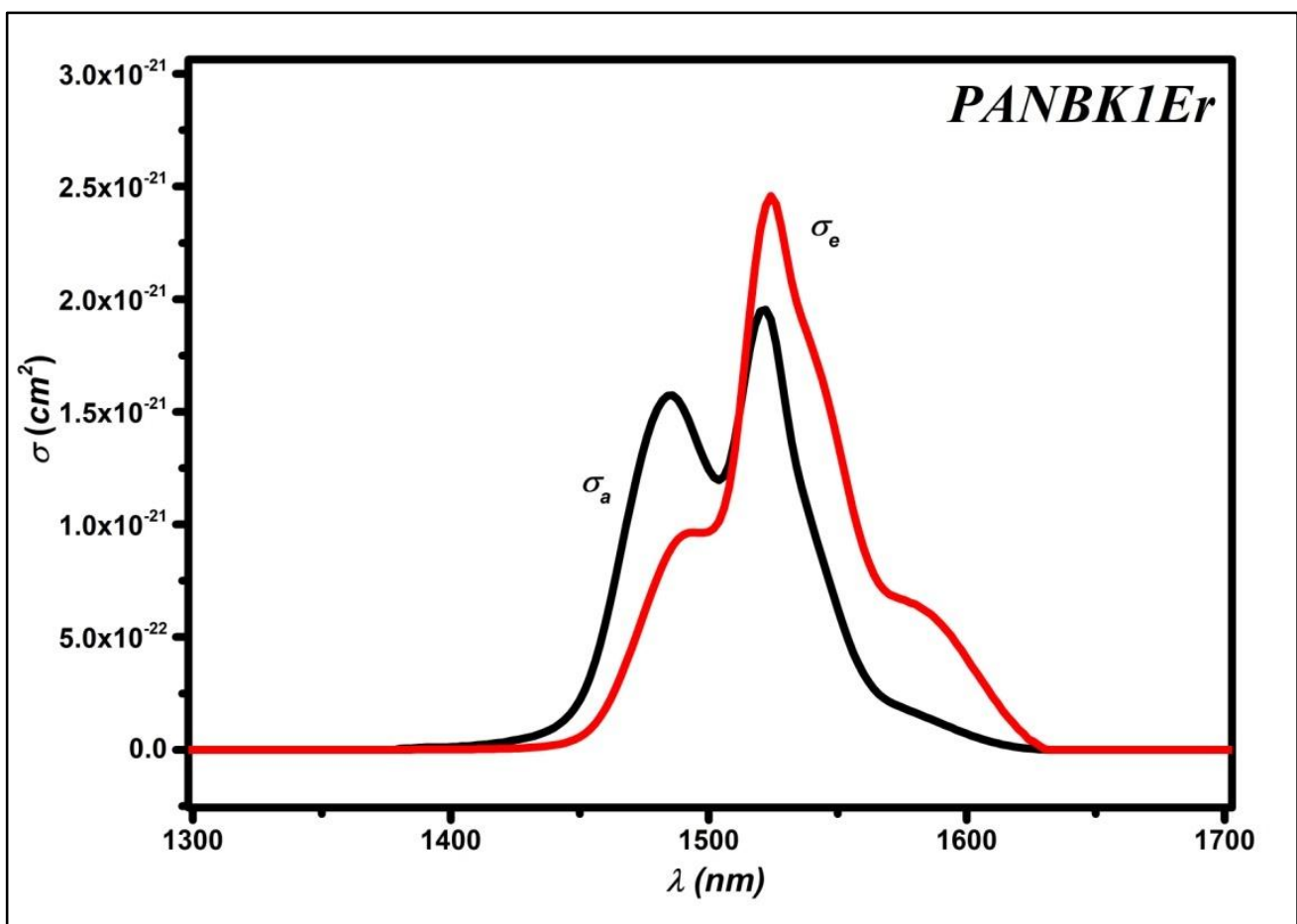

Fig.5.The absorption ( $\sigma \mathrm{a})$ and emission $(\sigma \mathrm{e})$ cross-sections of $4 \mathrm{I} 13 / 2 \rightarrow 4 \mathrm{I} 15 / 2$ transition vs wavelength in PANBK1.5Er.

The internal gain coefficient $(G)$ as a function of wavelength $\lambda$ can be estimated by means of the formula

$$
G(\lambda)=\sigma_{e}(\lambda) N_{2}-\sigma_{a}(\lambda) N_{1}
$$

Where $N_{1}$ and $N_{2}$ are the concentration of ions in the ground and excited state, respectively and $N_{1}+N_{2}=N$ where $N$ is being the total concentration of erbium ions in the sample) [E.Desurvire 1994]. The population inversion rate is given by

$$
P=\frac{N_{2}}{N}
$$

Fig.6 displays internal gain coefficient spectra as a function of inverted population rate. From this spectrum, it is observed that lasing would be achieved around $1596 \mathrm{~nm}$ with only $20 \%$ Population inversion $(P=0.2)$. A gain of $0.1 \mathrm{~dB} \cdot \mathrm{cm}^{-1}$ and nearly a flat band width are obtained. When increasing $P$, the gain's peak shifts to the shorter wavelength. For complete population inversion $(P=1)$ the peak centered at $1522 \mathrm{~nm}$, the effective bandwidth $=64.8 \mathrm{~nm}$ and the gain is equal to $9.67 \mathrm{~dB} \mathrm{~cm}^{-1}$. 


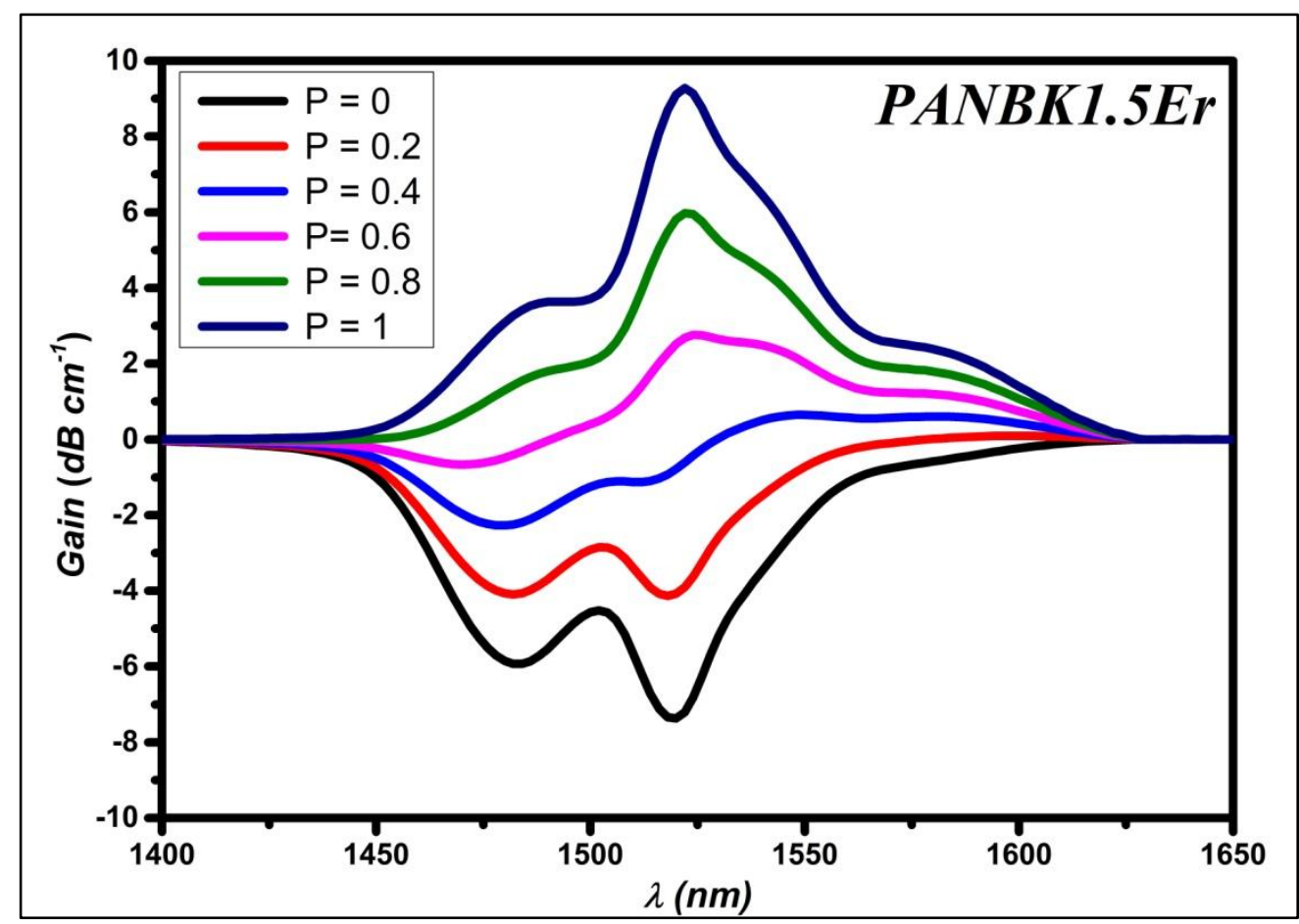

Fig.6. The gain spectra as a function of inverted population rate $(\mathrm{P}=0,0.2,0.4,0.6,0.8$ and 1) in PANBK1.5Er glass.

\section{Conclusion}

$\mathrm{Er}^{3+}$ doped Na-Al-Ba-K phosphate glasses have been prepared by melt quenching technique. Absorption spectra have been analyzed using the Judd-Ofelt theory. The Judd-Ofelt parameters of the present glass is smaller than other compared glasses which indicates that lower rigidity of the medium, lower covalency of the $\mathrm{Er}-\mathrm{O}$ bond and asymmetry around $\mathrm{Er}^{3+}$ site.. Higher radiative lifetime for the ${ }^{4} I_{13 / 2}$ level of $\mathrm{Er}^{3+}$ ions has been noticed compared to the other $\mathrm{Er}^{3+}$ doped glasses. The emission cross-section has been evaluated using Mc-Cumber theory hence the gain cross-section has been evaluated as a function of population inversion, which clarify that the amplification action achieved at $1.522 \mu \mathrm{m}$. These results obviously indicate that present glasses are suitable for laser as well as optical amplifiers around $543 \mathrm{~nm}$ and $1.522 \mu \mathrm{m}$ regions. 


\section{References}

A. A. Reddy, S. S. Babu, K. Pradeesh, C. J. Otton and G. V. Prakash, Optical properties of highly $\mathrm{Er}^{3+}$-doped sodium-aluminium-phosphate glasses for broadband $1.5 \mu \mathrm{m}$ emission, $\mathrm{J}$. Alloy. Compd. 509((2011) 4047-4052.

A. Lira, C. I. Camarillo, E. Camarillo, F. Ramos, M. Flores, U. Caldino, Spectroscopic characterization of $\mathrm{Er}^{3+}$ transitions in Bi4Si3O12, J. Phys.: Condens. Matter. 16 (2004) 59255936.

A. M. Y. Ohishi, M. Yamada, H. Ono, Y. Nishida, K. Oikawa, Gain characteristics of telluritebased erbium-doped fiber amplifiers for $1.5-\mu \mathrm{m}$ broadband amplification, Opt. Lett. 23(1998) 274-276.

B. R. Judd, Optical absorption intensities of rare earth ions, Phys. Rev. 127(1962) 750.

C.C.Santos, I.Guedes, C.K.Loong, L.A.Boatner, A.L.Moura, M. T. d. Araujo, C.Jacinto and M.V.D.Vermelho, Spectroscopic properties of $\mathrm{Er}^{3+}$-doped lead phosphate glasses for photonic application, Physics D: Applied Physics. 43(2) (2009) 025102. Doi:10.1088/0022$3727 / 43 / 2 / 025102$

C. K. Jorgensen and R. Reisfeld, Judd-Ofelt parameters and chemical bonding, Less-Common Met. 93 (1983) 107.

D. E. McCumber, Phys. Rev. 134(1964) A299-A306.

E.Desurvire (1994). Erbium-Doped Fiber Amplifiers, Principles and Applications. New York, John Wiley.

G. S. Ofelt, Intensities of Crystal Spectra of Rare-Earth Ions, Chemical Physics. 37(1962) 511520. Doi:10.1063/1.1701366.

K. Linganna, K. Suresh, S. Ju, W. T. Han, C. K. Jayasankar and V. Venkatramu, Optical properties of $\mathrm{Er}^{3+}$-doped $\mathrm{K}-\mathrm{Ca}-\mathrm{Al}$ fluorophosphate glasses for optical amplification at $1.53 \mu \mathrm{m}$, OPTICAL MATERIALS EXPRESS. 5(8) (2015) 1689-1703. DOI:10.1364/OME.5.001689

M. J. Digonett (2001). Rare-Earth-Doped Fiber Laser and Amplifier, Marcel Dekker, Inc.

M. P.Hehlen, MikhailG.Brik and KarlW.Krämer, 50th anniversary of the Judd-Ofelt theory: An experimentalist's view of the formalism and its application, Journal of Luminescence. 5136(2013) 221-239. Doi:10.1016/j.jlumin.2012.10.035.

M. Yamada, H. Ono, T. Kanamori and Y. Ohishi., Broadband and gain flattened amplifier composed of a $1.55 \mu \mathrm{m}$-band and $1.58 \mu \mathrm{m}$-band $\mathrm{Er}^{+3}$ - doped fiber amplifier in a parallel configuration Electron Lett. 33(1997) 710-711.

M.Yamane and Y.Asahara (2004). Glasses for Photonics, Cambridge University Press.

N. Luewarasirikul, N. Chanthima, Y. Tariwong and J. Kaewkhao, Erbium-doped calcium barium phosphate glasses for $1.54 \mu \mathrm{m}$ broadband optical amplifier, Materials Today: Proceedings. 5(6, Part 1) (2018) 14009-14016. Doi:10.1016/j.matpr.2018.02.053

P. Babu, H. J. Seo, K. H. Jang, R. Balakrishnaiah, C. K. Jayasankar, K.S. Lim and V. Lavín, 1.5 $\mu \mathrm{m}$ emission, and upconversion properties of $\mathrm{Er}^{3+}$-doped metaphosphate laser glasses, J. Opt. Soc. Am. B. 24 (2007) 2218-2228. 
Q. Qian, Q. Y. Zhang, H. F. Jiang, Z. M. Yang and Z. H. Jiang, The spectroscopic properties of $\mathrm{Er}^{3+}$-doped antimony-borate glasses, Physica B. 405(2010) 2220-2225.

Q. Qian, Y. Wang, Q. Y. Zhang, G. F. Yang, Z. M. Yang and Z. H. Jiang, Spectroscopic properties of $\mathrm{Er}^{3+}$-doped $\mathrm{Na}_{2} \mathrm{O}-\mathrm{Sb}_{2} \mathrm{O}_{3}-\mathrm{B}_{2} \mathrm{O}_{3}-\mathrm{SiO}_{2}$ glasses, Non-Cryst. Solids. 354(2008) 19811985.

RELIC (2013). https://www.lanl.gov/projects/feynman-center/deploying-innovation/intellectualproperty/software-tools/relic/index.php.

S. Georgescu, A. Ştefan and O. Toma, Judd-Ofelt analysis of Er-doped $\mathrm{CaSc}_{2} \mathrm{O}_{4}$ revisited, Journal of Luminescence. 199 (2018) 488-491. Doi:10.1016/j.jlumin.2018.03.086

S. Mohan, K. S. Thindb and G. Sharmab, Effect of $\mathrm{Nd}^{3+}$ Concentration on the Physical and Absorption Properties of Sodium-Lead-Borate Glasses, Brazilian Journal of Physics. 37(4) (2007) 1306-1313. Doi:10.1590/S0103-97332007000800019

W. J. Miniscalco and R. S. Quimby, General procedure for the analysis of $\mathrm{Er}^{3+}$ cross sections, Optics Letters. 16(1991) 258-260.

X. Qiao, X. Fan, M. Wang and X. Zhang, Up-conversion luminescence and near infrared luminescence of $\mathrm{Er}^{3+}$ in transparent oxyfluoride glassceramics, Opt. Mater. 27((2004) 597-603.

M. J. Weber, Probabilities for Radiative and Nonradiative Decay of $\mathrm{Er}^{3+}$ in $\mathrm{LaF}_{3}$, PHYSICAL REVIEW. 157(2) (1967) 262-272. DOI: 10.1103/PhysRev.157.262 


\section{الملخص باللغة العربية}

\section{الخواص الضوئية لزجاج الفوسفات المطعم بالاربيوم}

محمود محمد اسماعيل'، حازم فاروق'، محمد على سالم'، عادل عثيرى' ، ايناس كمال بطيشه'

'قشم فيزياء الجو امد، شعبة البحوث الفيزيقية، المركز القومى للبحوث، القاهرة، مصر

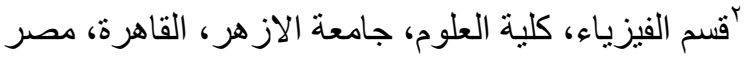

تم تحضير زجاج الفوسفات المطعم بايونات الاربيوم باستخدام طريقة الصهر ووالتبريد المحكوم. تم قياس طيف الامتصاص ومنه تم حساب معامل الامتصاص ومساحة مقطع الامتصاص للعينات. تم حساب مساحة مقطع الانبعاث باستخدام نموذج ماك كيمبر. تم تعبين الكسب كدالة فى معدل الانقلاب التسكينى والذى بين امكانية التكبير حول الطول الموجى 1097 نانو متر عند معدل انقلاب تسكينى •r\% فقط. تم استخدام نموذج جود اوفلت ومن ثم تم تعين الخواص الاشعاعية للانتقالات لوحظ ان فترة عمر المستوى ${ }^{4}{\text { للز }{ }_{13 / 2}}$ المحضر هى اكبر من مثيلاتها فى تركيبات اخرى. تشيركل النتائج الى ان الزجاج المحضر مناسب وواعد لتطبيقات الليزروعملية التكبير الضوئي حول الاطوال الموجية سج ع نانومتر و ror ا نانو متر. 